\title{
The evolutionary history of Drosophila buzzatii. XXXIII. Are Opuntia hosts a selective factor for the inversion polymorphism?
}

\author{
JUAN J. FANARA, ESTEBAN HASSON*, CONSTANTINA RODRÍGUEZ, MAURO \\ SANTOS $\uparrow \&$ ANTONIO FONTDEVILA $\dagger$ \\ GIBE, Departamento de Ciencias Biológicas, Facultad de Ciencias Exactas y Naturales, Universidad de Buenos \\ Aires, Ciudad Universitaria Pab. II, (1428) Buenos Aires, Argentina and †Departamento de Genética y Microbiología, \\ Universidad Autónoma de Barcelona, (08193) Bellaterra, Barcelona, Spain
}

\begin{abstract}
Previous work has shown fitness differences among chromosomal arrangements by means of selection component analysis in two Drosophila buzzatii natural populations, one of which is native to Argentina and the other a colonized population from Carboneras, Spain. Founder effects or niche shifts were proposed to explain the differences observed in the pattern of pleiotropic effects of inversions on fitness components. In this paper, we address the possible role of niche shifts by determining whether differential attraction to, oviposition on, or utilization of the rotting cladodes of two different Opuntia species (O. quimilo and O. ficus-indica) occurred among individuals carrying different second chromosome karyotypes in a natural Argentinian population. Through the analysis of more than 2500 individuals comprising five different life cycle stages associated with the necroses of these two cactus species, we found that the distributions of inversion frequencies in samples of adult flies, third instar larvae and emerging adults collected on both Opuntia species were not significantly different. Likewise, no evidence of differential oviposition was observed. These findings suggest that niche shifts cannot, solely, account for the changes observed in the Carboneras population. In addition, the selection component analysis did not reveal any significant relationship between chromosomal arrangements and the fitness components tested. These results suggest either that fitness differences might be too small to be detected or that the assumptions of the model concerning the mode of selection may not be tenable in the studied population.
\end{abstract}

Keywords: cactus hosts, Drosophila buzzatii, habitat selection, inversion polymorphism, natural selection.

\section{Introduction}

Drosophila buzzatii is a cactophilic species of the repleta group that breeds on the decaying cladodes of Opuntia cacti and in the rotting stems of a few columnar cactus species in Argentina (Hasson et al., $1992 b)$. It has recently colonized passively the Old World and Australia (Barker et al., 1985; Fontdevila, 1989). In these areas, several studies have characterized the yeast community present in the necrotic cacti (Barker et al., 1984; Peris, 1991). Likewise, there exists a good description of its chromosomal

\footnotetext{
* Correspondence.
}

polymorphism in native (Fontdevila et al., 1982; Barker et al., 1985; Fontdevila, 1989, 1991; Hasson et al., 1995) and colonized areas (Fontdevila et al., 1981; Knibb \& Barker, 1988) and of allozymic variation as well (Barker et al., 1985; Sánchez, 1986).

Two papers have demonstrated a consistent relationship between the inversion polymorphism of $D$. buzzatii and several fitness components in two natural populations, one from Spain (Carboneras), in which the host plant is Opuntia ficus-indica (Ruiz et al., 1986) and the other from Argentina (Arroyo Escobar) where rotting cladodes of $O$. vulgaris are the breeding sites (Hasson et al., 1991). Based on the sharing of rare electrophoretic alleles as well as 
rare inversions, Fontdevila (1989) suggested that a population similar to Arroyo Escobar may be one of the original colonizing populations of some Spanish localities such as Carboneras. Those two studies revealed that: (a) the chromosomal arrangements present in both populations were the same, yet their frequencies were very different and (b) the patterns of the pleiotropic effects of inversions on fitness components were also different (Fontdevila, 1989; Hasson et al., 1991).

Two alternative, but nonmutually exclusive explanations can account for the repatterning of the fitness effects of inversions: (a) adaptation to a new host plant and/or (b) founder events during colonization.

In regard to the first explanation, differences among hosts may occur at two different but interacting levels. First, in the rotting tissues (hereafter called 'rots'), the microflora involved in the decay process provides trophic resources to the growing larvae and to adult flies. Recent studies have shown that yeast diversity and yeast species composition vary greatly among rots of different cactus species (Starmer et al., 1990). Barker et al. (1984) and Peris (1991) have also observed differences in yeast diversity among and within Opuntia species, both spatially (Barker et al., 1983, 1987; Starmer \& Phaff, 1983; Peris, 1991) and temporally (Peris, 1991). Secondly, cactus species may also differ in their chemical composition as shown by Kircher (1982) in the Sonoran desert, and, in turn, these differences may influence the microflora associated with their necroses. Finally, the interaction between yeast communities and cactus tissues may yield distinct volatile compounds which are used by the flies as clues for locating a suitable breeding site (Fogleman, 1982; Fogleman \& Abril, 1990).

The objective of the present paper is to determine whether two different host plants may be perceived as different patches of an heterogeneous environment by $D$. buzzatii flies carrying different chromosomal arrangements. The present study was performed in the locality of Termas de Rio Hondo where $D$. buzzatii breeds and feeds on the rotting cladodes of the endemic $O$. quimilo and the introduced and semicultivated $O$. ficus-indica. The specific questions addressed are: (a) are flies bearing distinct karyotypes differentially attracted to the rotting cladodes of two Opuntia species?, (b) are fitness differences between flies carrying different inversions constant across host species? and (c) are the effects of inversions on fitness similar to those described by Ruiz et al. (1986) or Hasson et al. (1991)?

(c) The Genetical Society of Great Britain, Heredity, 77, 500-508.

\section{Materials and methods}

The present study was conducted in an area between 10 and $15 \mathrm{~km}$ east of Termas de Rio Hondo city (Santiago del Estero Province, Argentina). This area belongs to the Western Chaco district of the Chaco Phytogeographic Dominion (Cabrera, 1976).

The study site is regularly occupied by three endemic cactus species: Opuntia quimilo and the columnars Stetsonia corynne and Cereus validus. $O$. ficus-indica is also present but confined to several plantations. $O$. quimilo and $O$. ficus-indica rotting pads were the only feeding and breeding resource during the experiment (October, 1989). Rotting stems of the columnar cacti were not found during our survey.

\section{Collecting methods}

Three different kinds of sample were obtained: (a) adult flies; (b) third instar larvae (TIL); and (c) immature adults (IA). For the adult flies rotting cladodes were localized during the morning and they were further employed as attractants for capturing flies at sunset. Adult flies were aspirated from the rots of $O$. quimilo (about 1000) and $O$. ficus-indica (800) and processed separately during the experiment.

Two hundred and seventy mature males (MM) collected on each Opuntia species were crossed individually with two virgin females homozygous for arrangements $2 \mathrm{j}$ and $4 \mathrm{~s}$. The salivary glands of one progeny larva from each successful cross were dissected and examined cytologically.

Captured females were employed to obtain two types of sample: eggs- 1 and eggs-2. For the former, 270 females collected on the rots of each species were placed individually in vials containing $5-6 \mathrm{~mL}$ of culture medium. The analysis of one progeny larva from each vial allowed the estimation of karyotypic and inversion frequencies. The comparisons of inversion frequencies between the adult male and eggs-1 samples across Opuntia species provide information on potential differential attraction to the two host plants.

The eggs- 2 samples were obtained by placing groups of 150 females in egg-collecting chambers. Eggs were collected during three consecutive days; on days 1 and 2 , three fresh vials, and on day 3 one fresh vial containing $18-20 \mathrm{~mL}$ of culture medium were seeded with 80 eggs (optimal density) collected from the chambers. Two replicate chambers were set up for $O$. quimilo females and only one for $O$. ficusindica. The salivary glands of 15 larvae from each vial were analysed cytologically. The rationale of 
these samples was to test the hypothesis of preferential oviposition through the comparison of inversion frequencies between the populations of eggs entering the rots of both Opuntia species.

Rotting cladodes of $O$. quimilo and $O$. ficus-indica were collected to obtain the second and third types of samples (see above). The third instar larvae (TIL) were sampled directly from the fermenting tissues of $18 O$. quimilo and $11 O$. ficus-indica rots, and a second set of rots of both species (13 of $O$. quimilo and 10 of $O$. ficus-indica) was employed to obtain samples of immature adults (IA). During 15 days after collection, the adults emerging from each rot were aspirated daily. Flies were sexed and random pairs from each rot ( 270 for $O$. quimilo and 230 for $O$. ficus-indica) were placed individually in vials. Inversion frequencies were estimated from the analysis of one progeny larva from each cross.

If the effects of inversions on larval viability are different in the two Opuntia hosts, the estimated frequency distributions should differ between TIL samples. A similar comparison between the IA samples provides information on differential pupal viability in the two resources.

\section{Selection component analysis}

The experimental protocol employed allows the determination of whether fitness differences exist between gene arrangements for several selection components, and also whether these differences are constant across host plants. This procedure, known as selection component analysis (SCA) involves comparisons of inversion frequencies between consecutive life cycle stages (Hasson et al., 1991; Ruiz et al., 1986). The fitness components studied through this approach were thoroughly described in Ruiz et al. (1986).

Briefly, this method allows the analysis of each of five fitness components by comparing the arrangement frequencies between two consecutive life cycle stages: (1) virility, MM vs. eggs-1 samples; (2) fecundity, eggs-1 vs. eggs-2; (3) larval viability, eggs-2 vs. TIL; (4) pupal viability, TIL vs. IA and (5) longevity; IA vs. MM samples.

Pairwise comparisons of arrangement frequency distributions between consecutive stages indicate the operation of directional selection when the compared frequencies are significantly different. However, nonsignificant differences do not rule out the operation of heterozygote advantage. For a complete discussion of the method and the underlying assumptions see Ruiz et al. (1986).

\section{Rearing and cytological methods}

A modified formula of David's (1962) killed yeast medium was employed during the experiment. In all cases, flies were transferred to fresh medium after $48 \mathrm{~h}$ to avoid crowding. Slides of polytene chromosomes were obtained according to Fontdevila et al. (1981).

\section{Statistical methods}

Two kinds of pairwise comparisons between samples were performed: (1) across Opuntia species for the same life cycle stage and (2) between consecutive stages. In most cases pairwise comparisons were performed by means of contingency tests. However, it should be noted that the inversion frequencies estimated for both the third instar larvae and immature adult samples are actually an average across rots; therefore, it is necessary to consider the among-rots (within species) component of variation. Thus, one-way anovas with Opuntia species as the main effect provide a better test for the significance of the differences of arrangement frequencies between the TIL and IA samples obtained from $O$. quimilo and $O$. ficus-indica. Prior to the ANOVA and because of the differences in sample sizes among rots, inversion frequencies were transformed according to Christiansen et al. (1976):

$\left(p_{i}-p_{o}\right)\left[2 N_{i} /\left(1-p_{o}\right) p_{o}\right]^{1 / 2}$

where $p_{i}$ is the frequency of a certain arrangement in rot $i, p_{o}$ is the mean frequency across rots of the same species and $N_{i}$ is the sample size for each rot.

\section{Results}

Comparison of inversion frequencies between samples across rot species

Absolute karyotypic frequencies in the samples of TIL and IA collected on $O$. quimilo and $O$. ficusindica rots are shown in Tables 1 and 2, respectively.

Total absolute karyotypic frequencies for third instar larvae and immature adults (summed across rots within Opuntia species) are shown in Table 3, along with eggs- 1 and eggs- 2 samples.

All samples were polymorphic for three second chromosome arrangements: st, $\mathrm{j}$ and $\mathrm{jz}^{3}$ and monomorphic for the rest of the chromosomes. Inversion frequencies do not differ significantly from those of recent collections (unpublished results) and from neighbouring populations (San Lorenzo in Fontdevila et al., 1982 and Santiago del Estero in Barker et 
Table 1 Absolute second chromosome karyotypic frequencies in the third instar larvae samples obtained from each Opuntia quimilo (a) and $O$. ficus-indica (b) rot collected in the Drosophila buzzatii population of Termas de Rio Hondo

\begin{tabular}{|c|c|c|c|c|c|c|}
\hline \multirow[b]{2}{*}{ Rot no. } & \multicolumn{5}{|c|}{ Karyotype } & \multirow[b]{2}{*}{$N$} \\
\hline & st $/$ st & $s t / j$ & $\mathrm{st} / \mathrm{jz} \mathrm{z}^{3}$ & $\mathrm{j} / \mathrm{j}$ & $\mathrm{j} / \mathrm{j} \mathrm{z}^{3}$ & \\
\hline \multicolumn{7}{|c|}{ (a) Opuntia quimilo } \\
\hline 1 & 4 & 5 & - & 4 & - & 13 \\
\hline 2 & 7 & 13 & 1 & 16 & - & 37 \\
\hline 3 & 13 & 16 & - & 3 & 1 & 33 \\
\hline 4 & 17 & 18 & - & 3 & - & 38 \\
\hline 5 & 20 & 8 & - & 1 & - & 29 \\
\hline 6 & - & 12 & 2 & 10 & - & 24 \\
\hline 7 & 11 & 25 & - & 5 & - & 41 \\
\hline 8 & 17 & 17 & - & 5 & - & 39 \\
\hline 9 & 11 & 23 & - & 3 & - & 37 \\
\hline 10 & 4 & 4 & 1 & 2 & - & 11 \\
\hline 11 & 17 & 13 & - & 6 & - & 36 \\
\hline 12 & 8 & 20 & - & 6 & 4 & 38 \\
\hline 13 & 3 & 7 & - & 2 & - & 12 \\
\hline 14 & - & 3 & - & 1 & 1 & 5 \\
\hline 15 & 8 & 19 & 1 & 11 & - & 39 \\
\hline 16 & 1 & 4 & 2 & - & 1 & 8 \\
\hline 17 & - & 1 & - & - & - & 1 \\
\hline 18 & - & 2 & - & - & - & 2 \\
\hline \multicolumn{7}{|c|}{ (b) Opuntia ficus-indica } \\
\hline 1 & 9 & 10 & 2 & 12 & 1 & 34 \\
\hline 2 & 9 & 9 & 2 & 3 & - & 23 \\
\hline 3 & 3 & 3 & - & 2 & 2 & 10 \\
\hline 4 & 11 & 23 & 1 & 1 & - & 36 \\
\hline 5 & 8 & 18 & 4 & 7 & 1 & 38 \\
\hline 6 & 13 & 16 & 1 & 4 & - & 34 \\
\hline 7 & 10 & 21 & - & - & - & 31 \\
\hline 8 & 10 & 9 & 1 & 3 & 1 & 24 \\
\hline 9 & 3 & 5 & - & - & - & 8 \\
\hline 10 & 10 & 13 & - & 3 & - & 26 \\
\hline 11 & 3 & 1 & - & - & - & 4 \\
\hline
\end{tabular}

$N$, total number of individuals sampled.

al., 1985) which also belong to the Western Chaco phytogeographic province (Hasson et al., 1995).

None of the $\chi^{2}$ values for goodness of fit to Hardy-Weinberg expectations was statistically significant at the 0.05 level (Table 3), suggesting that the population is mating at random.

Inversion frequencies for all samples are presented in Table 4. The comparisons between samples of the same life cycle stage across Opuntia hosts by means of contingency tests showed that inversion frequencies were not significantly different (eggs-1:
Table 2 Absolute second chromosome karyotypic frequencies in the samples of immature adults obtained from each Opuntia quimilo (a) and O. ficus-indica (b) rot collected in the Drosophila buzzatii population of Termas de Rio Hondo

\begin{tabular}{lcccccr}
\hline & \multicolumn{5}{c}{ Karyotype } \\
\cline { 2 - 5 } Rot no. & st/st & st/j & st/jz & $\mathrm{j} / \mathrm{j}$ & $\mathrm{j} / \mathrm{jz}^{3}$ & $N$ \\
\hline (a) Opuntia & quimilo & & & & & \\
1 & 4 & 9 & - & 4 & - & 17 \\
2 & 2 & 5 & - & - & - & 7 \\
3 & 1 & 5 & - & 4 & - & 10 \\
4 & 11 & 15 & - & 6 & - & 32 \\
5 & 2 & 4 & 1 & 1 & - & 8 \\
6 & 6 & 11 & 1 & 3 & 2 & 23 \\
7 & 1 & 3 & - & 6 & - & 10 \\
8 & 6 & 17 & - & 3 & - & 26 \\
9 & 3 & 5 & - & 1 & - & 9 \\
10 & 17 & 27 & - & 3 & - & 47 \\
11 & 14 & 13 & 1 & 8 & 1 & 37 \\
12 & 4 & 6 & - & 1 & - & 11 \\
13 & - & 4 & - & - & 1 & 5
\end{tabular}

(b) Opuntia ficus-indica

\begin{tabular}{rrrrrrr}
1 & 5 & 10 & - & 4 & - & 19 \\
2 & 2 & 3 & - & - & - & 5 \\
3 & 2 & 4 & - & - & - & 6 \\
4 & 5 & 7 & 1 & 2 & 2 & 17 \\
5 & 4 & 11 & - & - & - & 15 \\
6 & 1 & 4 & - & 1 & - & 6 \\
7 & 2 & 1 & - & 1 & - & 4 \\
8 & 3 & 2 & - & 1 & - & 6 \\
9 & 7 & 16 & - & 6 & 1 & 30 \\
10 & 24 & 46 & 3 & 18 & 1 & 92 \\
\hline
\end{tabular}

$N$, total number of individuals sampled.

$\chi_{2}^{2}=5.19, P=0.08$; eggs- $2: \chi_{2}^{2}=0.89, P=0.64$; adult males: $\chi_{2}^{2}=2.05, P=0.36$ ).

The data from the substrates were not grouped because inversion frequencies were shown to be heterogeneous among rots of $O$. quimilo for the TIL sample $\left(\chi_{15}^{2}=61.8, P<10^{-4}\right)$, marginally heterogeneous for the sample of larvae obtained from $O$. ficus-indica $\left(\chi_{9}^{2}=14.38, P=0.10\right)$ and the $O$. quimilo IA sample $\left(\chi_{12}^{2}=17.29, P=0.14\right)$, but nonsignificant for the IA emerged from $O$. ficus-indica $\left(\chi_{9}^{2}=4.47\right.$, $P=0.88$ ).

The analysis of population structure by means of $F$-statistics (Weir, 1990) for the samples of TIL revealed two contrasting patterns. On one hand, the estimated values of $F_{\mathrm{IS}}$ and $F_{\mathrm{IT}}$ for the $O$. quimilo and $O$. ficus-indica samples were not significant (see jackknife estimates and standard deviations in Table 5) suggesting that genotypic frequencies do not 
Table 3 Absolute karyotypic frequencies in the eggs-1, eggs-2, third instar larvae and immature adults (IA) samples of Drosophila buzzatii collected on the rots of Opuntia quimilo and $O$. ficus-indica

\begin{tabular}{|c|c|c|c|c|c|c|c|c|}
\hline \multirow[b]{2}{*}{ Karyotype } & \multicolumn{4}{|c|}{ Opuntia quimilo } & \multicolumn{4}{|c|}{ Opuntia ficus-indica } \\
\hline & Eggs-1 & Eggs-2 & Larvae & IA & Eggs-1 & Eggs-2 & Larvae & IA \\
\hline $\mathrm{st} / \mathrm{st}$ & 68 & 147 & 141 & 71 & 100 & 81 & 89 & 55 \\
\hline $\mathrm{st} / \mathrm{j}$ & 109 & 195 & 210 & 124 & 112 & 118 & 128 & 104 \\
\hline $\mathrm{st} / \mathrm{jz} \mathrm{z}^{3}$ & 2 & 13 & 7 & 4 & 4 & 4 & 11 & 4 \\
\hline $\mathrm{j} / \mathrm{j}$ & 40 & 84 & 78 & 39 & 34 & 35 & 35 & 33 \\
\hline $\mathrm{j} / \mathrm{j} \mathrm{z}^{3}$ & 6 & 6 & 7 & 4 & 6 & 4 & 5 & 4 \\
\hline $\mathrm{jz} / \mathrm{jz}^{3}$ & - & - & - & - & 1 & - & - & - \\
\hline$N$ & 225 & 445 & 443 & 242 & 257 & 242 & 268 & 200 \\
\hline$\chi^{2}$ & 0.15 & 1.97 & 0.23 & 1.81 & 0.18 & 0.57 & 1.50 & 1.66 \\
\hline
\end{tabular}

The $\chi^{2}$ goodness of fit to Hardy-Weinberg expectations is shown in the last row (degrees of freedom $=3$ in all cases).

$N$, number of individuals analysed.

Table 4 Relative frequencies of second chromosome arrangements in samples of five different life cycle stages of Drosophila buzzatii collected in association with the Opuntia quimilo and $O$. ficus-indica rotting cladodes

\begin{tabular}{lccccc}
\hline Arrangement & Males & Eggs-1 & Eggs-2 & Larvae & $\begin{array}{c}\text { Immature } \\
\text { adults }\end{array}$ \\
\hline $\begin{array}{l}\text { Opuntia quimilo } \\
\text { st }\end{array}$ & 0.563 & 0.549 & 0.564 & 0.563 & 0.558 \\
$\mathrm{j}$ & 0.406 & 0.433 & 0.415 & 0.421 & 0.425 \\
$\mathrm{jz}$ & 0.031 & 0.018 & 0.021 & 0.016 & 0.017 \\
$N$ & 229 & 450 & 890 & 886 & 484 \\
Opuntia ficus-indica & & & & & \\
st & 0.625 & 0.615 & 0.587 & 0.591 & 0.545 \\
$\mathrm{j}$ & 0.355 & 0.362 & 0.397 & 0.379 & 0.435 \\
$\mathrm{j} \mathrm{z}^{3}$ & 0.020 & 0.023 & 0.016 & 0.030 & 0.020 \\
$N$ & 248 & 514 & 484 & 536 & 400 \\
\hline
\end{tabular}

$N$, number of chromosomes sampled.

depart from expectations either in individual rots or in the total population. On the other hand, the estimated $F_{\mathrm{ST}} \mathrm{s}$ for both samples of larvae were significantly different from zero as suggested by the jackknife estimates over subpopulations (Table 5). These results suggest that inversion frequencies are heterogeneous among rots within cactus species. However, when $F_{\mathrm{ST}}$ values were compared according to the resampling method proposed by Van Dongen (1995) it was observed that after 1000 bootstrap resamples $F_{\mathrm{ST}}$ for the $O$. quimilo sample was highly significant $(P=0.001)$ and that differentiation among $O$. ficus-indica rots was nonsignificant
$(P=0.36)$, the difference between both estimates being significantly different from zero $(P=0.021)$. The estimated $F_{\mathrm{ST}}$ s for individual arrangements were compared within each cactus species by the same resampling methods. The most extreme values in $O$. ficus-indica (difference $=0.0126, P=0.37$ ) and $O$. quimilo (difference $=0.01, P=0.30$ ) were not significantly different from each other.

Thus, taking into account these patterns of among-rot differentiation, the comparisons of inversion frequencies between the TIL and IA samples across cactus species were performed by means of ANOVAS. Inversion frequencies proved to be more

(C) The Genetical Society of Great Britain, Heredity, 77, 500-508. 
Table 5 Analysis of population genetic structure by means of $F$-statistics (according to Weir, 1990) for the third-instar larvae samples of Drosophila buzzatii collected on Opuntia quimilo and $O$. ficus-indica

\begin{tabular}{lccc}
\hline Arrangement & $F_{\mathrm{IS}}$ & $F_{\mathrm{IT}}$ & $F_{\mathrm{ST}}$ \\
\hline Opuntia quimilo & & & \\
$\mathrm{st}$ & -0.042 & 0.018 & 0.058 \\
$\mathrm{j}$ & -0.038 & 0.013 & 0.049 \\
$\mathrm{jz}$ & -0.061 & -0.010 & 0.048 \\
All & -0.041 & 0.015 & 0.053 \\
Jackknifing over populations* & -0.041 & 0.014 & 0.053 \\
& $(0.051)$ & $(0.060)$ & $(0.043)$ \\
Opuntia ficus-indica & & & \\
st & -0.089 & -0.075 & 0.014 \\
$\mathrm{j}$ & -0.057 & -0.056 & 0.001 \\
jz & -0.038 & -0.028 & 0.009 \\
All & -0.071 & -0.064 & 0.007 \\
Jackknifing over populations* & -0.071 & -0.061 & 0.008 \\
& $(0.092)$ & $(0.098)$ & $(0.0007)$ \\
\hline
\end{tabular}

*Standard deviation in parentheses.

heterogeneous among rots within Opuntia species than between species for both the TIL $\left(F_{1,24}=0.008\right.$, $P=0.93)$ and IA $\left(F_{1,21}=0.308, P=0.59\right)$ samples.

\section{Selection component analysis}

Because the comparisons between samples collected from $O$. quimilo and $O$. ficus-indica did not yield significant differences, samples of the same life stage were pooled across host species for the SCA. None of the contingency tests comparing inversion frequencies between consecutive life cycle stages was significant suggesting the absence of virility selection $\left(\chi_{2}^{2}=0.16, P=0.92\right)$, fecundity $\left(\chi_{2}^{2}=1.67, P=0.43\right)$, larval viability $\left(\chi_{2}^{2}=2.16, P=0.34\right)$, pupal viability $\left(\chi_{2}^{2}=3.07, P=0.22\right)$ and longevity $\left(\chi_{2}^{2}=5.19\right.$, $P=0.08)$.

\section{Discussion}

The present results indicate that there are no significant differences among second chromosome karyotypes of $D$. buzzatii with regard to: (a) differential attraction, (b) female ovipositing behaviour and (c) differential performance, in relation to the utilization of the rotting cladodes of $O$. quimilo and $O$. ficus-indica.

The first stage of the host selection process, movement to and settling at a potential breeding site (settling behaviour, Jaenike, 1990), was analysed through the comparison between adult flies attracted to the rots of $O$. quimilo and $O$. ficus-indica. As adult flies attracted to both Opuntia species did not differ in their inversion frequencies, it can be argued that second chromosome arrangements do not show differential attraction to potential breeding sites. However, because inversion frequencies in the eggs1 samples are an average across sexes, the validity of this comparison rests on the assumption that the behavioural response to the hosts is identical in both sexes. The close fit to Hardy-Weinberg expectations suggests not only that chromosomal frequencies are similar in both sexes but also that the population is mating at random, as reported for other populations (Rodríguez et al., 1992; Barbadilla et al., 1994).

With regard to oviposition, inversion frequencies in the eggs-2 samples were not significantly different suggesting that females carrying different karyotypes oviposit irrespective of the Opuntia species where they were collected. However, this result must be taken with caution because both egg samples were obtained using the same stimulant for oviposition. In addition, we have to accept that female oviposition behaviour in the egg collecting chambers is the same as in nature and that no selection has occurred in the vials where larvae developed. Concerning the first point, inversion frequencies in samples of adults collected on $O$. vulgaris and fermented banana baits were not significantly different in the population of Arroyo Escobar (Rodríguez et al., 1992). Likewise, larval viability was high (more than 90 per cent) in the vials where larvae were reared. 
The larval stage is another instance in which habitat selection may take place through differential performance on environmental patches. The breeding sites where Drosophila larvae develop are discrete and ephemeral, and larval performance may depend on the site chosen by females. The comparisons between samples of third instar larvae and immature adults obtained from $O$. quimilo and $O$. ficus-indica rots do not show any evidence of differential fitness and allow us to rule out this kind of spatial heterogeneity in the maintenance of the inversion polymorphism in Termas de Río Hondo.

The analysis of population structure showed that among-rot differentiation was significant only for the $O$. quimilo sample. One possible explanation for these contrasting patterns may be selective differentiation among $O$. quimilo breeding sites, as previously observed in a $D$. buzzatii Spanish population living on O. ficus-indica (Santos et al., 1989; Santos, 1994). However, under this hypothesis, it might be expected that individual $F_{\mathrm{ST}}$ estimates for each arrangement would be different, which is not the case, either in $O$. quimilo or in $O$. ficus-indica, suggesting random differentiation as the most plausible explanation.

The analysis of yeast species and their relative abundance in a sample of the rots showed that Pichia cactophila and Candida sonorensis were the most abundant and, although heterogeneity among rots within species was high, the difference between species was not significant (F. Peris, personal communication). Pichia cactophila is not only the most preferred species for feeding and oviposition by $D$. buzzatii in Australian populations (Vaçek, 1982; Vaçek et al., 1985), but it was also shown that larvae feed preferentially on this species, and that this preference is independent of the inversion karyotype (Peris et al., 1991). This evidence provides the ecological support to our conclusion that the rots of $O$. ficus-indica and $O$. quimilo are not perceived as different patches of an heterogeneous environment by $D$. buzzatii flies carrying different second chromosome karyotypes.

The SCA performed in Termas de Rio Hondo did not show any significant relationship between second chromosome arrangements and the fitness components tested, a result that is in contrast with previous studies (Ruiz et al., 1986; Hasson et al., 1991).

SCA, which is among the most sensitive methods for the detection of natural selection, has its weakest statistical power near the values predicted by the null hypothesis, i.e. absence of selection (Endler, 1986, p. 99). However, in our previous study in Arroyo Escobar, in which our sample sizes were similar to the present, it was shown that this method is sensitive enough (Hasson et al., 1991).

Another possible explanation for the lack of detection might be related to the assumptions on the mode of selection (Endler, 1986). The SCA devised by Ruiz et al. (1986) can only detect directional selection. However, when inversion frequencies between consecutive life cycle stages are not different, it cannot be concluded that selection is not operating. Heterotic balance, for example, will produce no frequency change between life cycle stages. Although departure from Hardy-Weinberg expectations is a very weak test of selection, the absence of an excess of heterozygotes suggests that heterotic balance is not operating. In addition, $F_{\text {Is }}$ values in both host plants, though negative, are not significant.

Correspondingly, if some form of frequencydependent selection is acting, and the population is at or near equilibrium, selection will only be detected when the population is disturbed away from equilibrium. The origins of the populations studied in Ruiz et al. (1986) and in Hasson et al. (1991) are recent. The Spanish population could be no more than 200 years old (Fontdevila et al., 1981), and in Arroyo Escobar (Hasson et al., 1991), the host population of $O$. vulgaris grows on both sides of a railway which is not older than 100 years. Therefore it can be argued that the associations between fitness components and inversions observed by Ruiz et al. (1986) and Hasson et al. (1991) could be the result of perturbations that took the populations away from equilibrium.

Differences in resource utilization among populations were suggested as one possible explanation for the pattern of geographical differentiation in the inversion polymorphism of $D$. buzzatii (Hasson et al., 1995). However, the present results suggest that shifts from one Opuntia species to another cannot, solely, account for the genetic changes observed and founder effects, alone, and/or drift-selection interaction may have been the main forces driving divergence.

Fontdevila (1989) argued that the observed loss of low frequency arrangements and allozymic alleles could be interpreted as evidence of founder effects during the colonization of the Old World by $D$. buzzatii. Nonetheless, it is not clear how the reorganization of the fitness effects of inversions can take place after a founder event (Fontdevila, 1989). In theory, chance alterations of the frequency of coadapted gene complexes are subjected to natural selection leading to a fitness reweighting of the pleiotropic antagonistic effects (Carson \& Temple- 
ton, 1984). In fact, there is some experimental evidence for the effect of founder events on the additive genetic covariance structure for polygenic traits in bottleneck populations of the house fly (Bryant, 1989).

Research work in D. buzzatii has shown a significant relationship between the inversion polymorphism and body size (Ruiz et al., 1991; Hasson et al., 1992a) and other morphometric traits (Norry et al., 1995). The analysis of these traits in original and colonized populations may provide the genetic framework to test the hypothesis of a genetic reorganization after the founder event.

\section{Acknowledgements}

The authors wish to thank to W. F. Eanes, D. Futuyma, J. Jaenike M. McCartney and two anonymous reviewers for the critical reading of the manuscript. The original version of this manuscript was finished while E. H. was the recipient of a CONICET (Argentina) fellowship at the Department of Ecology \& Evolution, SUNY, Stony Brook (U.S.A.). This work was supported by Universidad de Buenos Aires grants EX-050/92 and EX099/94 awarded to E. H. and by DGICYT (Ministerio de Educación, Spain) grant $\mathrm{PB} 85 / 0071$ and $\mathrm{PB} 89 / 0325$ awarded to A. F. E. H. is a member of Carrera del Investigador Científico (CONICET).

\section{References}

BARBADILla, A., RUIZ, A., SANTOS, A. AND FONTDEVIlA, A. 1994. Mating pattern and fitness-component analysis associated with inversion polymorphism in a natural population of Drosophila buzzatii. Evolution, 48, $767-780$.

BARKER, J. S. F., TOLL, G. L., EAST, P. D., MIRANDA, M. AND PHAFF, H. J. 1983. Heterogeneity of the yeast flora in the breeding sites of cactophilic Drosophila. Can. J. Microbiol., 29, 6-14.

BARKER, J. S. F., EAST, P. D., PHAFF, H. J. AND MIRANDA, M. 1984. The ecology of the yeast flora in necrotic Opuntia cacti and of associated Drosophila in Australia Microbial Ecol., 10, 379-399.

BARKER, J. S. F., SENE, F. DE M., EAST, P. D. AND PEREIRA, M. A. Q. R. 1985. Allozyme and chromosomal polymorphism of Drosophila buzzatii in Brazil and Argentina. Genetica, 67, 161-170.

BARKER, J. S. F., STARMER, W. T. AND VAÇEK, D. C. 1987. Analysis of spatial and temporal variation in the community structure of yeasts associated with decaying Opuntia cactus. Microbial Ecol., 14, 267-276.

BRYANT, E. H. 1989. Multivariate morphometrics of bottlenecked populations. In: Fontdevila, A. (ed.) Evolution- ary Biology of Transient Unstable Populations, pp. 19-31. Springer-Verlag, Berlin.

CABReRA, A. 1976. Regiones Fitogeográficas de la Argentina. Editorial ACME, Buenos Aires.

CARSON, H. L. AND TEMPLETON, A. R. 1984. Genetic revolutions in relation to speciation phenomena: The founding of new populations. Ann. Rev. Ecol. Syst., 15, 97-131.

CHRISTIANSEN, F. B., FRYDENBERG, O., HJORTH, J. P. AND SIMONSEN, V. 1976. Genetics of Zoarces viviparus. IX. Geographic variation at the three phosphoglucomutase loci. Hereditas, 83, 245-256.

DAVID, J. 1962. A new medium for rearing Drosophila in axenic conditions. Drosoph. Inf. Serv., 36, 128.

ENDler, J. A. 1986. Natural Selection in the Wild. Princeton Univerity Press, Princeton, NJ.

Fogleman, J. C. 1982 . The role of volatiles in the ecology of cactophilic Drosophila. In: Barker, J. S. F and Starmer, W. T. (eds) Ecological Genetics and Evoluton. The Cactus-Yeast-Drosophila Model System, pp. 191-206. Academic Press, Sydney.

FOGLEMAN, J. C. AND ABRIL, J. R. 1990. Ecological and evolutionary importance of host plant chemistry. In: Barker, J. S. F., Starmer, W. T. and MacIntyre R. (eds) Ecological and Evolutionary Genetics of Drosophila, pp. 121-143. Plenum Press, New York.

FONTDEVILA, A. 1989. Founder effects in colonizing populations: The case of Drosophila buzzatii. In: Fontdevila, A. (ed.) Evolutionary Biology of Transient Unstable Populations, pp. 74-95. Springer-Verlag, Berlin.

FONTdevilA, A. 1991. Colonizing species of Drosophila. In: Hewitt, G., Johnston, M. and Young, J. P. W. (eds) Molecular Techniques in Taxonomy, pp. 249-269. Springer-Verlag, Berlin.

FONTDEVIlA, A., RUiz, A., ALONSO, G. AND OCANA, J. 1981. Evolutionary history of Drosophila buzzatii. I. Natural chromosomal polymorphism in colonized populations of the Old World. Evolution, 35, 148-157.

FONTDEVIlA, A., RUIZ, A., OCAÑA, J. AND ALONSO, G. 1982. Evolutionary history of Drosophila buzzatil. II. How much has chromosomal polymorphism changed in colonization?. Evolution, 36, 843-851.

HASSON, E., VILARD1, J. C., NAVEIRA, H., FANARA, J. J., RodrigueZ, C., REIG, O. A. AND FONTDEVIlA, A. 1991. The evolutionary history of Drosophila buzzatii. XVI. Fitness component analysis in an original natural population from Argentina. J. Evol. Biol., 4, 209-225.

HASSON, E., FANARA, J. J., RODRIGUEZ, C., VILARDI, J. C., REIG, O. A. AND FONTDEVILA, A. 1992a. The evolutionary history of Drosophila buzzatii. XXIV. Second chromosome inversions have different average effects on thorax length. Heredity, 68, 557-563.

HASSON, E., NAVEIRA, H. AND FONTDEVIla, A. 1992b. The breeding sites of the Argentinian species of the Drosophila mulleri complex (subgenus Drosophila-repleta group). Rev. Chilena de Hist. Nat., 65, 319-326.

HASSON, E., RODRIGUEZ, C., FANARA, J. J., NAVEIRA, H., REIG, O. A. AND FONTDEVILA, A. 1995. The evolutionary 
history of Drosophila buzzatii. XXVI. Macrogeographic patterns of inversion polymorphisms in New World populations. J. Evol. Biol., 8, 369-384.

JAENIKE, J. 1990. Factors maintaining genetic variation for host preference in Drosophila. In: Barker, J. S. F., Starmer, W. T. and MacIntyre R. (eds) Ecological and Evolutionary Genetics of Drosophila, pp. 195-207. Plenum Press, New York.

KIRCHER, H. W. 1982. Chemical composition and its relationship to Sonoran desert Drosophila. In: Barker, J. S. F. and Starmer, W. T. (eds) Ecological Genetics and Evoluton. The Cactus-Yeast-Drosophila Model System, pp. 143-158. Academic Press, Sydney.

KNIBB, W. R. AND BARKER, J. S. F. 1988. Polymorphic inversion and esterase loci complex on chromosome 2 of Drosophila buzzatii. II. Spatial variation. Aust. J. Biol. Sci., 41, 239-246.

NORRY, F. M., VILARDI, J. C., FANARA, J. J., HASSON, E. AND RODRÍGUEZ, C. 1995. An adaptive chromosomal polymorphism affecting size-related traits, and longevity selection in a natural population of Drosophila buzzatii. Genetica, 96, 285-291.

PERIS, F. 1991. Adaptación Trófica y Evolutiva de Drosophila en Zonas Áridas. Ph.D. Thesis, Universidad Autónoma de Barcelona Bellaterra Barcelona, Spain.

PERIS, F., QUEZADA-DIAZ, J. E., BARBADILLA, A., RUIZ, A., SANTOS, M. AND FONTDEVIla, A. 1991. Definición del nicho trófico de Drosophila buzzatii. VIII Seminario de Genética de Poblaciones y Evolución, Sant Cugat del Valles. Universidad Autónoma de Barcelona., Spain.

RODRÍGUEZ, C., HASSON, E., FANARA, J. J. AND VILARDI, J. C. 1992. Second chromosome polymorphism of Drosophila buzzatii is not associated with gametic selection and does not affect mating pattern. Génét. Sél. Évol., 24, 179-186.

Ruiz, A., FOnTDEVIla, A., Santos, M., SEOANe, M. AND TORROJA, E. 1986. The evolutionary history of Drosophila buzzatii. VIII. Evidence for endocyclic selection acting on the inversion polymorphism in a natural population. Evolution, 40, 740-755.
RUIZ, A., SANTOS, M., BARBADILLA, A., QUEZADA-DíAZ, J. E., HASSON, E. AND FONTDEVILA, A. 1991. Genetic variance for body size in a natural population of Drosophila buzzati. Genetics, 128, 739-750.

SANCHEZ, A. 1986. Relacimes Filogenéticas en las Clusters buzzatii $y$ martensis de Drosophila. Ph.D. Thesis, Universidad Autónoma de Barcelona Bellaterra, Barcelona, Spain.

SANTOS, M. 1994. Heterozygote deficiencies under Levene's population subdivision structure. Evolution, 48, 912-920.

SANTOS, M., RuIZ, A. AND FONTDEVILA, A. 1989. The evolutionary history of Drosophila buzzatii. XIII. Random differentiation as a partial explanation of chromosomal variation in a structured natural population. Am. Nat., 133, 183-197.

STARMER, W. T. AND PHAFF, H. J. 1983. Analysis of the community structure of yeasts associated with the decaying stems of cactus. II. Opuntia species. Microbial Ecol., 9, 247-259.

STARMER, W. T., LACHANCE, M.-A., PHAFF, H. J. AND HeED, w. B. 1990. The biogeography of yeasts associated with decaying cactus tissue in North America, the Caribbean, and Northern Venezuela. In: Hecht, M. K., Wallace, B. and MacIntyre, R. J. (eds) Evolutionary Biology, vol. 24, pp. 253-296. Plenum Press, New York.

VAÇEK, D. C. 1982. Interactions between microorganisms and cactophilic Drosophila in Australia. In: Barker, J. S. F. and Starmer, W. T. (eds) Ecological Genetics and Evoluton. The Cactus-Yeast-Drosophila Model System, pp. 115-190. Academic Press, Sydney.

VAÇEK, D. C., EAST, P. D., BARKER, J. S. F. AND SOLIMAN, M. H. 1985. Feeding and oviposition preferences of Drosophila buzzatii for microbial species isolated from its natural environment. Biol. J. Linn. Soc., 24, 175-187.

VAN DONGEN, s. 1995. How should we bootstrap allozyme data? Heredity, 74, 445-447.

WEIR, B. 1990. Genetic Data Analysis. Sinauer Associates, Sunderland MA. 